\title{
EDITORIAL
}

\section{Childhood cancer in the UK: achievements and legacy of six decades of research in Oxford}

\author{
British Journal of Cancer (2018) 119:659-660; https://doi.org/10.1038/s41416-018-0222-7
}

\section{SUMMARY}

Three papers on epidemiological research into childhood cancer, conducted over six decades at the University of Oxford, record the many achievements of these studies and their considerable impact, both in the UK and internationally. Future research should benefit from plans to make available the substantial resources that were collected over this time.

\begin{abstract}
MAIN
Large-scale epidemiological studies have a vital role in investigating the causes of childhood cancer and are the focus of three new papers that summarise long-term ground-breaking research carried out mainly at the University of Oxford. The first of these papers ${ }^{1}$ concerns the Oxford Survey of Childhood Cancers (OSCC), a large case-control study originally conducted within the Institute of Social Medicine, before moving to the University of Birmingham. The other two papers ${ }^{2,3}$ summarise research conducted over nearly 40 years by the Childhood Cancer Research Group (CCRG), based around the National Registry of Childhood Tumours (NRCT). I collaborated with the authors of these papers while working at the National Radiological Protection Board (latterly the Health Protection Agency's Radiation Protection Division) and I served on CCRG's Scientific Advisory Group. Consequently, I have been fortunate to witness many of the achievements that resulted from these studies.
\end{abstract}

\section{OXFORD SURVEY OF CHILDHOOD CANCERS}

To initiate a detailed epidemiological study of all childhood cancer deaths in England and Wales (and later Scotland) in the early 1950s was an amazing achievement, and a testament to the perseverance and tenacity of the OSCC's founder, Alice Stewart. The most notable result from the OSCC was the link found between childhood cancer and irradiation of the fetus from antenatal X-raying. This finding, which Bithell et al. ${ }^{1}$ discuss at length, led in large part to the reduced use of antenatal X-raying. In addition, the OSCC confirmed an association with the father's tobacco use that had been reported in smaller studies and was one of the first studies to report a raised cancer risk among children with a sibling who had also died of cancer. ${ }^{1}$ The OSCC has some important limitations, which the authors highlight; e.g., the restriction to fatal cases of cancer and the potential for recall bias and for errors in data recording. Nevertheless, provided that the study's limitations and their likely impact are well understood, I would concur with Bithell et al.'s view that data from the OSCC might still have a role in future research; e.g., when investigating rarer cancers for which many other studies have smaller numbers of cases. I am therefore pleased to hear of the plans to make data from this study generally available.

\section{CHILDHOOD CANCER RESEARCH GROUP}

The CCRG was established in 1975, after a government committee recommended setting up a national registry of childhood malignancies. Over the next four decades, the CCRG compiled data on about 57,000 cases of childhood cancer registered in Great Britain (and latterly also Northern Ireland) during 1962-2010. By drawing upon not only routinely collected data on incidence and deaths but also data from paediatric oncologists and clinical trials, the completeness and accuracy of the NRCT is likely to be very high. That said, childhood cancer might have been under-recorded in the past, as indicated by an analysis linking time trends in incidence rates to changes in diagnostic or registration procedures. ${ }^{4}$ The NRCT data were highly valuable in studies of the descriptive epidemiology of childhood cancer incidence and survival, both within the United Kingdom and-as Draper et al. ${ }^{2}$ highlight-as a leading component of international studies. The CCRG also collected data on congenital anomalies and genetic conditions, which permitted more detailed examination of familial factors than was possible using the OSCC; e.g., it highlighted the continued cancer risk among carriers of retinoblastoma gene mutations. ${ }^{5}$ Furthermore, prompted by a study of cancer in the offspring of radiation workers, a series of controls was established for many of the cases. Together with birth records, this allowed case-control studies to be conducted on diverse topics such as birthweight, paternal occupation and proximity to high-voltage power lines. ${ }^{2}$ The association with childhood leukaemia found in the original power line study attracted considerable attention, although-as Draper et al. ${ }^{2}$ point out-this association was not seen in more recent UK data or in studies in other countries.

The CCRG conducted high quality epidemiological studies on a broad range of topics over many years, but the area that attracted perhaps the greatest interest was its research on ionising radiation. ${ }^{3}$ Investigations into childhood cancer-and particularly childhood leukaemia-near nuclear installations have received much attention over several decades, and CCRG's contributions to these studies and to reports by the UK Government's Committee on Medical Aspects of Radiation in the Environment (COMARE) have been very important. Data from the NRCT were valuable not only in studying childhood cancer incidence in small areas around these installations (e.g., in COMARE's 10th report ${ }^{6}$ ), but also in placing these results in a wider context. Specifically, by analysing data on small area incidence throughout Great Britain, COMARE found that the geographical distribution of childhood cancers was non-random. ${ }^{7}$ As well as these geographical studies, Kendall et al. ${ }^{3}$ document how data for controls matched to these cases permitted detailed investigations of possible links with, for example, parental preconception irradiation and exposure to natural radiation. The association found between childhood leukaemia and natural gamma ray radiation ${ }^{8}$ is especially interesting and it would be good to see if this finding could be 
replicated in cohort or case-control studies elsewhere; that said, few other countries would have sufficiently large and detailed data to allow such replication.

\section{FUTURE}

Following the end of the OSCC and the closure of the CCRG, what happens next? For me the issue is not where childhood cancer research is conducted but rather that resources are available to enable continued epidemiological research into childhood cancer in the United Kingdom and globally. Public Health England, which is now responsible for childhood cancer registration in England, is incorporating NRCT data dating back to 1985 into its ENCORE database. ${ }^{9}$ Nevertheless, like Draper et al., ${ }^{2}$ I believe that the full NRCT dataset covering cases diagnosed over almost half a century would still be a valuable research resource and-as with the OSCC - I am pleased that it might be available for future projects that would further our understanding of the causes of childhood cancer and might assist with prevention and treatment. This would be a fitting legacy to six decades of childhood cancer research in Oxford.

\section{ADDITIONAL INFORMATION}

Competing interests: The author declares no competing interests.

Note: This work is published under the standard license to publish agreement. After 12 months the work will become freely available and the license terms will switch to a Creative Commons Attribution-NonCommercial-Share Alike 4.0 Unported License).
Colin R. Muirhead ${ }^{1}$

${ }^{1}$., Newcastle upon Tyne, UK Correspondence: Colin R. Muirhead (colin.muirhead6@virginmedia.

com)

\section{REFERENCES}

1. Bithell, J. F., Draper, G. J., Sorahan, T. \& Stiller C. A. Childhood cancer research in Oxford I: The Oxford Survey of Childhood Cancers. Br J Cancer (2018).

2. Draper, G. J., et al. Childhood cancer research in Oxford II: The Childhood Cancer Research Group. Br J Cancer (2018).

3. Kendall, G. M., et al. Childhood cancer research in Oxford III: The work of CCRG on ionising radiation. $\mathrm{Br} J$ Cancer (2018).

4. Kroll, M. E., Carpenter, L. M., Murphy, M. F. G. \& Stiller, C. A. Effects of changes in diagnosis and registration on time trends in recorded childhood cancer incidence in Great Britain. Br. J. Cancer 107, 1159-1162 (2012).

5. Sanders, B. M., Jay, M., Draper, G. J. \& Roberts, E. M. Non-ocular cancer in relatives of retinoblastoma patients. Br. J. Cancer 60, 358-365 (1989).

6. Committee on Medical Aspects of Radiation in the Environment (COMARE). COMARE 10th Report: The incidence of childhood cancer around nuclear installations in Great Britain. (Health Protection Agency, Chilton, 2005).

7. Committee on Medical Aspects of Radiation in the Environment (COMARE). COMARE 11th Report: The distribution of childhood leukaemia and other childhood cancers in Great Britain 1969-1993. (Health Protection Agency, Chilton, 2006).

8. Kendall, G. M. et al. A record-based case-control study of natural background radiation and the incidence of childhood leukaemia and other cancers in Great Britain during 1980-2006. Leukemia 27, 3-9 (2013).

9. Public Health England. Childhood cancer registration in England: 2015 to 2016. (Public Health England, London, 2016). www.ncin.org.uk/view?rid=3296. 